\title{
Quality of Life after Palliative Mastectomy for Stage IV Breast Cancer in Elderly
}

\section{Chen YC and Ikhwan SM*}

Department of Surgery, Universiti Sains Malaysia, Kubang Kerian, Kelantan, Malaysia

\begin{abstract}
Advance breast cancer still becomes a debate among surgeons either to act aggressively in view of the survival outcome. However the problem may arise from the disease progress which can be complicated by sepsis due to infection, severe bleeding, foul odour and sensation of heaviness. The decision will be more complicated if it occurs among geriatric patients. Here we presented a case of neglected right breast cancer which was treated late when it occupied the whole breast. The histopathological results revealed Poorly Differentiated Infiltrating Ductal Carcinoma and CT Scan showed liver and lung metastases (Stage IV). Palliative mastectomy was done to prevent complication such as infection and sepsis, bleeding and to reduce the sensation of heaviness. The discussion focused on the role of mastectomy to improve quality of life in elderly with advance breast cancer.
\end{abstract}

Keywords: Palliative mastectomy; advance breast cancer; Stage IV breast cancer

\section{Introduction}

Breast carcinoma continues to dominate as the most common malignancy in women. As life expectancy increases at a steady rate, more patients with breast cancer will be over age 65 (elderly age group). Palliative care is defined as the active total care of patients whose disease is not responsive to curative treatment. Palliation is, simply in its purest sense, a treatment to enhance quality of life. Each patient's definition of quality of life is unique. As such, it is important to treat each person as an individual and to continue to view the patient holistically [1].

Therefore, palliative mastectomy is by means to prevent and palliate breast or chest symptoms, or pain in order to allow patients to resume active lifestyle as symptomless as possible with the fewest possible adverse effects of the treatment [2].

\section{Case Report}

A 78-year-old lady presented to Surgical Ward with 4 months history of painless right breast lump. Initially it was small in size thus patient did not bother to seek any medical treatment. However the mass started to enlarge progressively within the next 2 months. It ruptured on the overlying skin and ulcerated. It started to bleed upon touch and produced bad odour. The patient at last sought medical attention when the mass occupied the whole breast and caused heaviness sensation. Upon examination, it was a fungating cauliflower like mass occupying the entire right breast (Figure 1) with area of slough and necrotic tissue.

The true cut biopsy of the mass revealed poorly differentiated

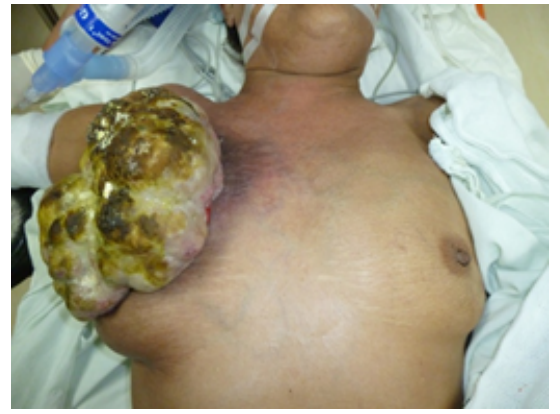

Figure 1: Right huge fungating breast cancer which occupy the whole breast infiltrating ductal carcinoma. The patient was sent to palliative chemotherapy after CT scan staging showed multiple liver and lung metastases, which consist of Taxane, Cyclophosphamide and Adriamycin. After third cycle of chemotherapy the mass just shrunk about $30 \%$ of total volume. The patient refused to continue the chemotherapy due to its adverse effect. The decision for palliative mastectomy to improve the patient's quality of life. Intraoperative the mass infiltrated to the underlying pectoralis major muscle and bleeding upon excision (Figure 2) Primary closure of the skin successfully done and the patient recovered well postoperatively.

\section{Discussion}

It is imperative to weigh the benefits and risks of the method of treatments with consideration of the sequelae of the aging processes in elderly patient with Stage IV breast carcinoma $[3,4]$.

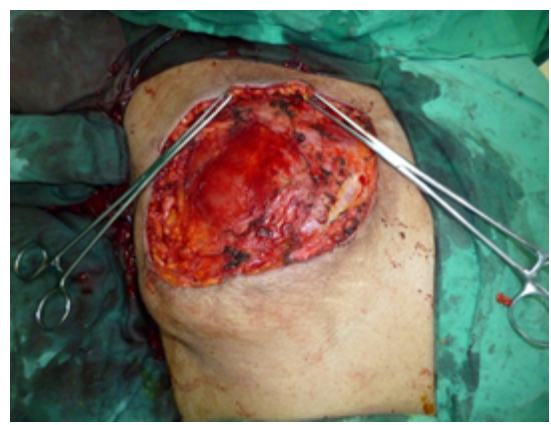

Figure 2: The appearance of right chest wall after the mastectomy. The pectoralis major muscle which was infiltrated by the tumour was excised exposing the intercostal muscles (arrow)

*Corresponding author: Ikhwan SM, lecturer, USM, Surgery, USM Kubang Kerian Kota Bharu, Kota Bharu, Kelantan 16150, Malaysia, Tel: +60 179278535/ +60 97676774; Fax: +60 97676775; E-mail: ikhwansani@yahoo.com.my

Received August 19, 2014; Accepted September 26, 2014; Published September 30,2014

Citation: Chen YC, Ikhwan SM. Quality of Life after Palliative Mastectomy for Stage IV Breast Cancer in Elderly. Journal of Surgery [Jurnalul de chirurgie] 2014; 10(3): 243-244 DOI: 10.7438/1584-9341-10-3-9

Copyright: ( 2014 Chen YC, et al. This is an open-access article distributed under the terms of the Creative Commons Attribution License, which permits unrestricted use, distribution, and reproduction in any medium, provided the original author and source are credited. 
Elazar et al. revealed the results of study that elderly women with breast cancer should be treated by surgical methods that offer the best chance of cure regardless of the patient's age. However, elderly women should be generally treated in a more conservative manner than younger women. In advanced stage of cancer, simple mastectomy is done for palliative purposes [4].

Associated illnesses were of particular concern because of the impact on surgical risks as well as the quality of life in elderly patient. Comorbidities and frailty are also important determinants of the outcome of treatment $[3,5]$.

Though, it was unclear that palliative surgery would otherwise improve clinical outcomes [6]. Eun Young Kim, et al. showed that palliative mastectomy did not afford significant survival advantage [7].

However, the timing of surgical intervention has been found to be crucial. It was demonstrated in a study that surgical resection of the intact primary tumor and axillary nodes more than three months after the diagnosis of stage IV breast cancer was associated with improved metastatic progression-free survival and a trend towards better overall survival rate [8].

There was a study done on the predictors of the quality of life and found that arm problems, doctor communication, comorbidities and age had significant impact in patients' quality of life. Despite the vast literatures on this subject, it is still rather vague especially in elderly patient as not all of them were successfully recruited in the study [5].

Healthcare providers must not forget the patient's dignity, selfworth and personal goals. After multiple hospitalizations, elderly patients often tend to become debilitated and deconditioned quickly.
They are highly distressed by the loss of independent self-care and thus, can slide into depression. Comprehensive rehabilitation services should be provided to alleviate and improve their quality of life [9].

\section{Conflict of interest}

Authors have no conflict of interest to disclose.

\section{References}

1. Krouse RS, Jonasson O, Milch RA, Dunn GP (2004) An evolving strategy for surgical care. J Am Coll Surg 198: 149-155.

2. Kumar A, Shah LL, Khanna S, Khanna NN (1987) Preoperative chemotherapy for fungating breast cancer. J Surg Oncol 36: 295-298.

3. Hunt KE, Fry DE, Bland KI (1980) Breast carcinoma in the elderly patient: an assessment of operative risk, morbidity and mortality. Am J Surg 140: 339-342.

4. Amsterdam E, Birkenfeld S, Gilad A, Krispin M (1987) Surgery for carcinoma of the breast in women over 70 years of age. J Surg Oncol 35: 180-183.

5. Engel J, Kerr J, Schlesinger-Raab A, Eckel R, Sauer H, et al. (2003) Predictors of quality of life of breast cancer patients. Acta Oncol 42: 710-718.

6. Bafford AC, Burstein HJ, Barkley CR, Smith BL, Lipsitz S, et al. (2009) Breast surgery in stage IV breast cancer: impact of staging and patient selection on overall survival. Breast Cancer Res Treat 115: 7-12.

7. Eun Young Kim, et al. (2007) The clinical characteristics and predictive factors of stage IV breast cancer at the initial presentation: A review of a single institute's data. J Breast Cancer 10: 101-106

8. Rao R, Feng L, Kuerer HM, Singletary SE, Bedrosian I, et al. (2008) Timing of surgical intervention for the intact primary in stage IV breast cancer patients. Ann Surg Oncol 15: 1696-1702.

9. Cheville AL (2005) Cancer rehabilitation. Semin Oncol 32: 219-224 